\title{
Coating with Different Doses of Fertilizer in Vinhático Seeds
}

\author{
Priscila Gonçalves Figueiredo De Sousa*, Henrique Duarte Vieira, Amanda Justino Acha \\ Center of Agricultural Science and Technology, State University of Northern Fluminense, Campos dos Goytacazes, Brazil \\ Email: *priscila.gfs@hotmail.com
}

How to cite this paper: Sousa, P.G.F., Vieira, H.D. and Acha, A.J. (2017) Coating with Different Doses of Fertilizer in Vinhático Seeds. American Journal of Plant Sciences, 8, 2554-2568.

https://doi.org/10.4236/ajps.2017.810173

Received: August 24, 2017

Accepted: September 26, 2017

Published: September 29, 2017

Copyright (c) 2017 by authors and Scientific Research Publishing Inc. This work is licensed under the Creative Commons Attribution International License (CC BY 4.0).

http://creativecommons.org/licenses/by/4.0/

\begin{abstract}
Plathymenia reticulata Benth belongs to the family Fabaceae. It has its own hardwood for luxury furniture, and it is also used in construction. The coating consists in applying thin and uniform layers of inert adhesive mechanism in order to increase the seed size, altering his shape, texture and color, in addition to enabling common use of nutrients, fungicides, insecticides and microorganisms beneficial. The goal of this study was to evaluate the physical and physiological seed's quality of mahogany coated with different doses of fertilizer. The treatments were: $\mathrm{T} 1$ : sand + lime; T2: sand + lime $+25 \mathrm{~g}$ of fertilizer; T3: sand + lime $+50 \mathrm{~g}$ of fertilizer; T4: sand + lime $+75 \mathrm{~g}$ of fertilizer; T5: sand + lime $+100 \mathrm{~g}$ of fertilizer, and control with uncoated seeds. Later, the seeds were evaluated in laboratory and greenhouse. The coating increased up to $91 \%$ weight of one thousand seeds without the treatment coated fertilizer. The presence of nutrient seed coating decreases his germination. The doses of fertilizer used were harmful to germination, IVG, emergency and IVE, but did not affect seedlings development.
\end{abstract}

\section{Keywords}

Fabaceae, Coating, Fertilizer, Emergency

\section{Introduction}

Plathymenia reticulata Benth belongs to the family Fabaceae, subfamily Mimosoideae, and it is commonly known, in Portuguese, as vinhático and vinhático-da-mata. It is a heliophytic and selective xerophytic species which presents an irregular and discontinuous seed dispersal within its distribution area. From this species it is produced hardwood suitable for making luxury furniture, sliced ve- 
neers, and wood panels. Furthermore, this hardwood is also used in construction for internal finishes, frames, window blinds, linings, doors and to make wine barrels [1].

The far-reaching economic, social and environmental potential of the vinhatico, combined with the few works found in the literature, validates how important it is to carry out studies on this species, making it necessary to elaborate methodologies for its efficient multiplication, conservation and maintenance [2]. That would justify the studies on seeds of this species, taking into account the physical and physiological aspects of such seeds, since the species is propagated by them.

The technique of seed coating has been used for a long time, applied mostly to vegetable, forest and ornamental seeds. It consists in applying thin and uniform layers of adhesive, inert materials to the seeds, with the goal of increasing their size, their shape, texture and color. Furthermore, this technique enables the mutual use of nutrients, fungicides, insecticides and beneficial micro-organisms [3].

Besides, the coating protects the seeds from temperature and humidity variations, both in the soil and when they are stored [4]. Another advantage of seed coating is the ease of incorporating chemicals such as macro and micronutrients with the possibility of raising production, especially in areas that have high levels of crop management technology [5].

The ability to add nutrients to seed turns fertilization and crop fertility into a more effective and less costly process, because fertilizers are constantly suffering with high rates of losses in the field due to leaching and soil erosions that still carry mineral and organic fraction essential to plant development [6].

In addition to the losses of fertilizers through soil, native forest species still lack information about the nutritional requirements, both for the production of seedlings and for the establishment and initial development of plants in the field [7].

Coating seeds with macro and micronutrients is presented as a possible solution to the problems described above, because the localized application of fertilizers offers many advantages, such as: initial source of nutrients for the seedling, lower contact of the nutrient with the soil and the possibility to form more uniform and vigorous plant stands, in addition to decreasing the costs of replanting and thinning.

Thus, the objective of this work was to evaluate the effect of coats with different doses of fertilizers on the quality of vinhático seeds.

\section{Material and Methods}

The seeds of vinhático were purchased from the company Caiçara Comércio de Sementes. Initially, the wings were removed, and then the damaged or malformed seeds were separated. After this step, the seeds were mechanically sca- 
rified using $\mathrm{n}^{\circ} 36$ sandpaper in order to ensure that they were completely soaked.

For the coat, the proportions between the filling material and the seeds were of $3: 1(\mathrm{p} / \mathrm{p})$ : for each $50 \mathrm{~g}$ of seeds, $150 \mathrm{~g}$ of filling material were used. This amount of material was divided into twelve portions, and each layer was composed of two portions of $12.5 \mathrm{~g}$ of filling material, adding up to a total of 6 layers. As adhesive solution, it was used PVA-based glue diluted in water at $70^{\circ} \mathrm{C}$, at a rate of 1:1 (v/v), according to [8].

For seed coating, we used, as filling material, sand + limestone [9] and increasing doses of fertilizer NPK 4-14-7 + boron and zinc, being the following treatments: T1: sand + limestone; T2: sand + limestone $+25 \mathrm{~g}$ of fertilizer (mixture of N-P-K + boron and zinc); T3: sand + limestone $+50 \mathrm{~g}$ of fertilizer; T4: sand + limestone $+75 \mathrm{~g}$ of fertilizer; $\mathrm{T} 5$ : sand + limestone $+100 \mathrm{~g}$ of fertilizer; T6: control, with uncoated seeds.

It was performed the mixture of fertilizers, with $200 \mathrm{~g}$ of NPK 4-14-7, $10 \mathrm{~g}$ of boron (boric acid) and $10 \mathrm{~g}$ of zinc (zinc sulfate). The fertilizers were macerated before being mixed. Then, they were applied to the intermediate layers of coating to prevent it from being in direct contact with the surface of the seeds, while it was also protected by the outer layers.

The arrangement of the layers of filling materials in the seed coats was as it follows: T1: 6 portions of sand +6 portions of limestone; T2: 5 parts of sand +2 portions of fertilizer +5 portions of limestone; T3: 4 portions of sand +4 portions of fertilizer +4 portions of limestone; T4: 3 portions of sand +6 portions of fertilizer +3 portions of limestone; T5: 2 portions of sand +8 portions of fertilizer + 2 portions of limestone.

The coating process was conducted in a Newpack coating pan, model N-10. The equipment has a stainless steel vat that revolves at a speed of $40 \mathrm{rpm}$, spray with pressure of 4 bars, hot air at $40^{\circ} \mathrm{C}$ to dry seeds, regulators and timers.

The seeds were placed inside the vat of the coating pan, along with a portion of the filling material. Then, the spray of adhesive solution was applied 3 times, with one-minute intervals between each application. Next, another portion of the filling material was put on the seeds, followed by another application of adhesive solution. After that, the hot air blower was activated for 1 minute. This process corresponded to one layer of coating. Six layers were made for the complete coating of the seeds (Figure 1).

After coated, the seeds had their physical and physiological characteristics evaluated.

The procedures for the evaluation of such characteristics were:

Water content (WC) and weight of 1000 seeds (WTS): according to [10].

Germination test (GT): performed with four replications of 50 seeds, germinated in paper towels, previously moistened with water equivalent to 2.5 times 


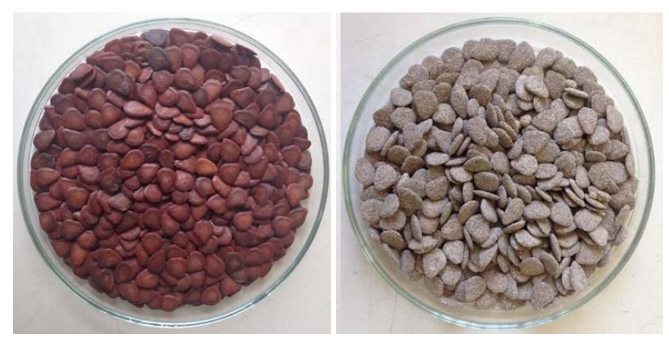

(a)

(b)

Figure 1. Uncoated vinhatico seeds (Control Treatment) (a); Vinhatico seeds coated with sand + limestone (Treatment 1) (b).

the weight of the paper. Then, the paper towels were brought to a BOD germinator regulated at a constant temperature of $25^{\circ} \mathrm{C}$, light/dark for $8 / 16$ hours. The evaluations were carried out at days 10 and 16, taking account of the number of normal, anomalous and infested seedlings and non-germinated seeds, according to the criteria set out in Regra para Análise de Sementes [11].

Germination speed index (GSI) - it was conducted together with the germination test, and the evaluations were carried out every two days, from sowing until the end of the test. The index was calculated based on the Maguire's Formula [12].

Emergence in greenhouse (\% E) - four replications of 50 seeds were sown in plastic trays containing washed sand, corresponding to each one of the coating treatments with filling material. The trays were kept in a greenhouse and the counting of normal seedlings emerged took place on the 16th day.

Emergence speed index (ESI) - it was conducted together with the assessment of seedlings emergence in a greenhouse, and the evaluations were carried out every two days until the 16th day after sowing. The index was calculated based on the Maguire's Formula [12].

Length of aerial part (LAP) and root length (RL) - the length of the aerial part and the length of the root was measured using a millimeter ruler, after 60 days in the greenhouse, in four replications of ten plants washed and chopped, separating the aerial part and the root from the stem of the plant.

Fresh and dry mass from the aerial part and of the root-after measuring the length of the aerial part and the length of the root, they were put on an analytical balance to obtain the values of fresh mass. Both parts were placed in paper bags, separately, and put in a greenhouse with forced-air ventilation at $60^{\circ} \mathrm{C}$ to dry, during 72 hours. Next, they were weighed in an analytical balance.

The experiments in the laboratory and in the greenhouse were conducted in a completely randomized design, comprehending six treatments with four replications of 50 seeds. The data obtained were subjected to analysis of variance and to comparison of means by Duncan's test, being 5\% the level of significance, with the aid of the software ASSISTAT ${ }^{\circledast}$ [13]. 


\section{Results and Discussions}

The coating process used in the seeds of vinhatico resulted in an increase of their weight and size (Figure 1 and Table 1).

The results of the weight of 1000 seeds, coated and uncoated, showed that the coating used in all treatments significantly increased the weight of the seeds, a mass gain of more than $91 \%$, as it is with the coating treatment without fertilizer, which weighed $20.9 \mathrm{~g}$ while the control weighed only $10.9 \mathrm{~g}$ (Table 1 ).

According to the analysis, weight gain was observed in the coating from $4.08 \mathrm{~g}$ to $10.02 \mathrm{~g}$ in coated seeds compared to uncoated ones, as it can be observed in Table 1.

Coating without fertilizer was the one that provided higher WTS (10.02 g), and that is due to the fact that both the sand and the limestone stick homogeneously to the seeds during the coating process, in relation to treatments containing fertilizer. [14] working with the coating of seeds of Estilosantes Campo Grande, observed that the texture of the limestone and of the sand results in the formation of a structure with more granules around the seed, which causes mass gain.

The statistical analysis of the data related to WTS makes it possible to observe that there was no significant difference between the treatment without fertilizer and the treatment with $100 \mathrm{~g}$ of fertilizer in the coating, due to the fact that both the sand and the large amount of fertilizer in the treatment with $100 \mathrm{~g}$ of fertilizer in its composition, stuck homogenously to the coating of the seeds of vinhatico, giving them an increased weight of 1000 seeds and a greater value in the coating (Table 1).

According to [15], the increase in weight and size of the seed is due to the easy distribution of seeds during sowing, manual or mechanical.

As it can be seen in Figure 2, along with the coating treatments, analyses were made on uncoated seeds, or control seeds, for the analysis and comparison of the

Table 1. Weight of 1000 seeds ( $\mathrm{g}$ ) and coating increment $(\mathrm{g})$ in seeds of vinhatico (Plathymenia reticulata Benth.) without coating and coated with sand + limestone + increasing doses of fertilizer. ${ }^{\star}$ Control—-seeds without coating.

\begin{tabular}{cccc}
\hline $\begin{array}{c}\text { Treatments } \\
{ }^{*} \text { Control }\end{array}$ & Weight of 1000 Seeds $(\mathrm{g})$ & Coating Increment $(\mathrm{g})$ & Coating Increment (\%) \\
0 g fertilizer & $10.97 \mathrm{c}$ & 0 & 0 \\
25 g fertilizer & $20.99 \mathrm{a}$ & 10.02 & 91.3 \\
50 g fertilizer & $17.20 \mathrm{~b}$ & 6.23 & 56.7 \\
75 g fertilizer & $16.79 \mathrm{~b}$ & 5.82 & 53.0 \\
100 g fertilizer & $15.05 \mathrm{~b}$ & 4.08 & 37.1 \\
\hline
\end{tabular}

Averages followed by the same letter do not differ from each other by Tukey test, at $5 \%$ probability. 


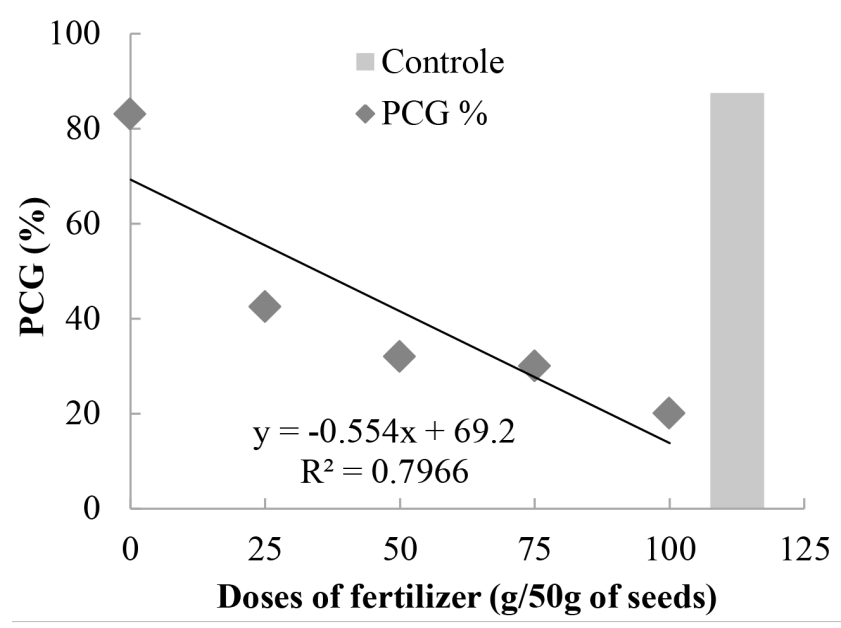

(a)

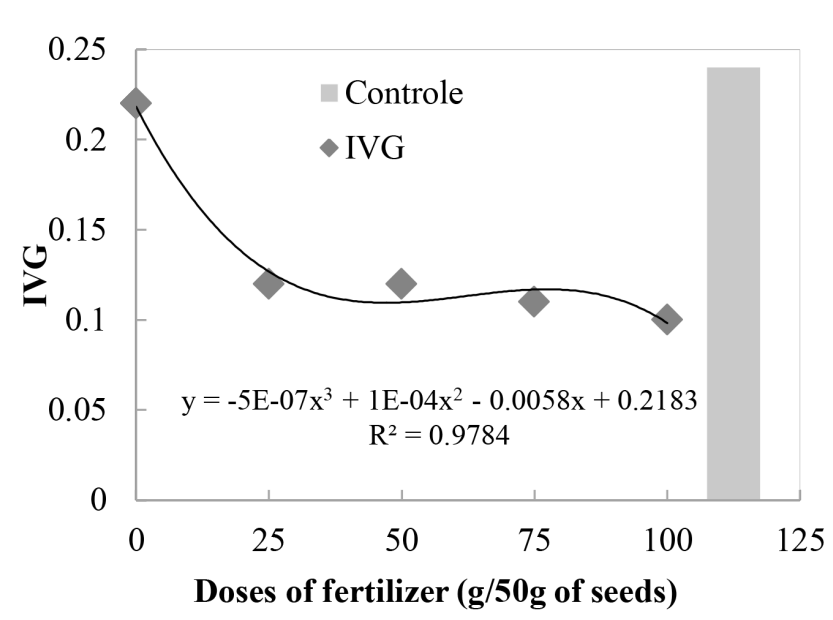

(c)

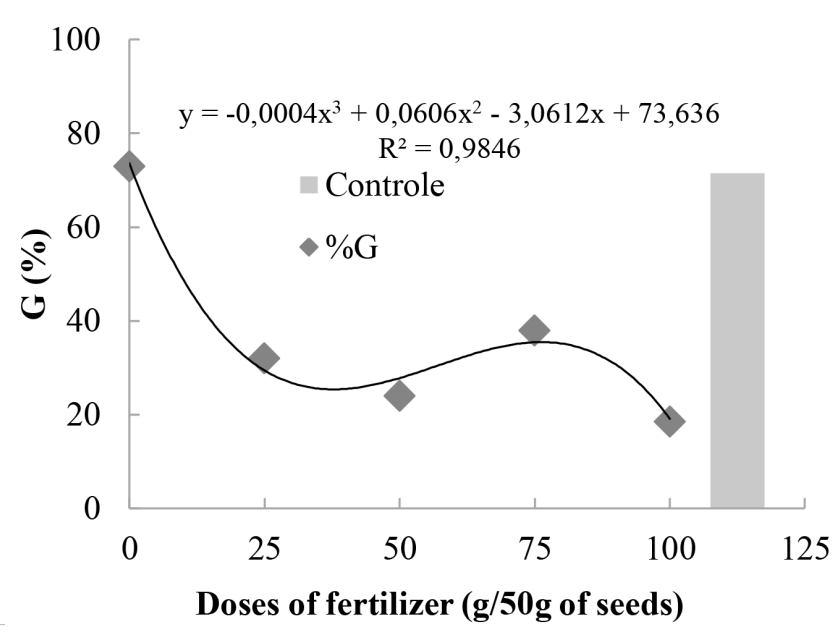

(b)

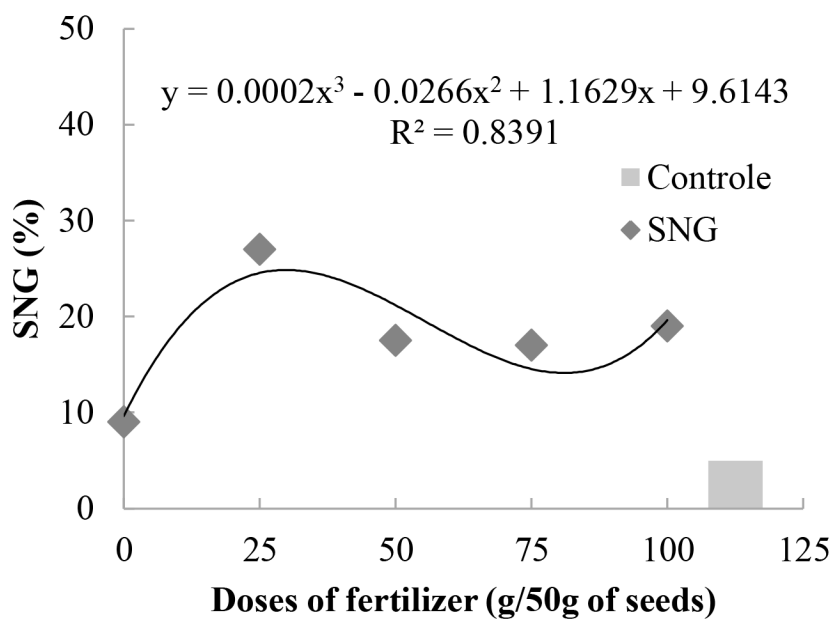

(d)

Figure 2. (a) Percentage of first germination count (PCG); (b) Percentage of germination (G\%); (c) Germination speed index (IVG); (d) Non-germinated seeds (SNG) in seedlings from seeds of vinhatico coated with increasing doses of fertilizer $(0,25,50$, 75 and $100 \mathrm{~g} / 50 \mathrm{~g}$ of seeds) and uncoated seeds (grey column).

development of seedlings that received coating. This control treatment proved to be more vigorous in some characteristics, such as First Germination Count, Germination Speed Index, Percentage of Emergence and Emergence Speed Index, whereas it does not present the physical barrier formed by the coating, which can reduce its gas exchanges, hindering the germination process. However, for this experiment, no significant differences were observed between the control treatment and the coating treatment without fertilizer.

For the first germination count (FGC), according to regression analysis, it was observed linear, descending behavior for the doses of fertilizer used. Thus, the higher the dose the lower the percentage of FGC. As for the percentage of germination (\% $\mathrm{G})$, according to regression analysis, it was observed cubic behavior for the doses of fertilizer used. 
Evaluating the results of the first germination count (FGC) and percentage of germination (G), it can be observed that the treatments with the highest doses of fertilizer were the most harmful to the germination of vinhatico seeds. The treatment with $25 \mathrm{~g}$ of fertilizer promoted decrease of approximately $50 \%$ in the (FGC) and in $(G)$. It is worth mentioning that there were no significant differences between the control seeds and the seeds coated without fertilizer, showing that the negative effect on low FGC and G is due to the high amounts of fertilizer in the coating and not an effect of the coating itself.

According to [16], the increase of saline concentration in the substrate affects the germination of seeds, because it expands the osmotic potential of the solution and decreases the water potential. Furthermore, when associated with the toxic effect of salts, it interferes in the process of absorption of water by seeds.

It was observed in this work that the seeds absorbed water, although the water did not reach its minimum content in the seed in order to promote its germination, making it seem like the coating competed against the seed for the water available in the substrate, therefore lowering the percentage of FGC and G.

The [17] states that the answer to the application of nutrients in the coating depends on the source of nutrient used, on the species and on how the nutrient is supplied, because different sources of the same nutrient may interfere with different intensity with the germination of seeds. [17] also says that the use of soluble saline fertilizer as coating material for seeds has been destructive to germination and to the initial growth of seedlings, considering that it impairs the absorption of water.

Already [18] reports that some materials used in the coating of the seeds, as well as the dosage, can cause immediate phytotoxic effects on germination or reduce the physiological quality of seeds.

The authors [19], working with sorghum seeds treated with zinc $(0,3.57,7.14$, 14.28 and $28.56 \mathrm{~g}$ of zinc per $\mathrm{kg}$ of seeds), using zinc sulfate heptahydrate as a source of zinc, also observed that germination reduced when the doses of fertilizers increased.

As it was observed for germination with different doses of fertilizer in the coating of vinhatico seeds, the GSI also presented cubic regression. However, as it can be seen in Figure 2(c), there was no significant difference between the control (column) and the coated seeds without fertilizer (dose zero).

Although the coating forms a physical barrier that must be overcome by the radicle, it was not detrimental to the speed of germination. The negative effect in relation to this variable was due to the doses of fertilizer used, because as the dose increased, the speed of germination decreased. On the other hand [20], while studying pelleted seeds of mutamba, evaluated the effect of four different sizes of pellets, and came to the conclusion that while there is an increase in the size of the pellet, it occurs a decrease of emergence and of the GSI, assigning this decrease to the size of the pellet and not to its composition, different than what 
was observed in this work, when the doses of fertilizers influenced the speed of germination but not the coating.

Through regression analysis regarding the percentage of non-germinated seeds (NGS), it was observed that there was cubic behavior for this variable, being the values for NGS higher for coatings with fertilizer in relation to the coating without fertilizer (Figure 2(d)).

Through the analysis of variance, it was found that there was no significance only for the variable of abnormal seedlings (AS) as it can be seen in Figure 3(a). That is, the damage caused by doses of fertilizer is not reflected in this feature of the seeds.

In the evaluation of infested seedlings (IS), it was observed that the increase of IS presented cubic regression, with the highest rates of IS being found in doses of 50 and $100 \mathrm{~g}$ of fertilizer (Figure $3(\mathrm{~b})$ ). The effect of the attack of pathogens can

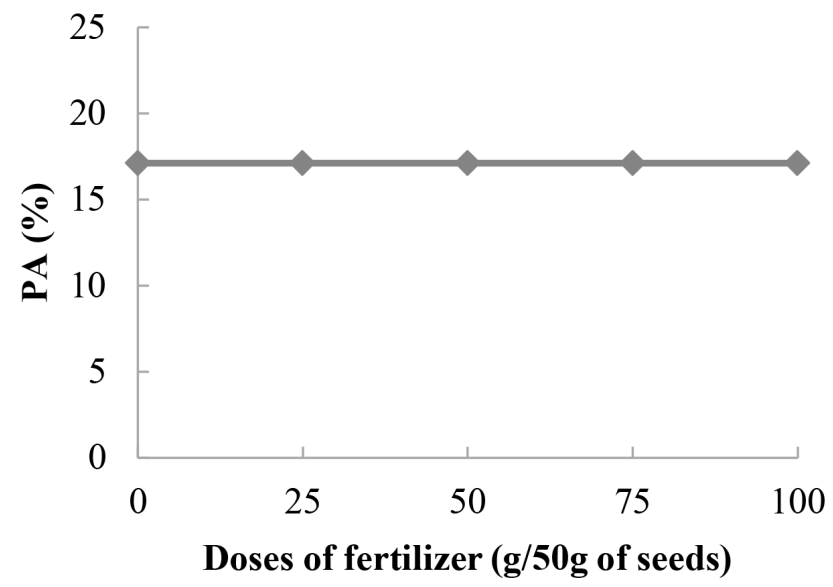

(a)

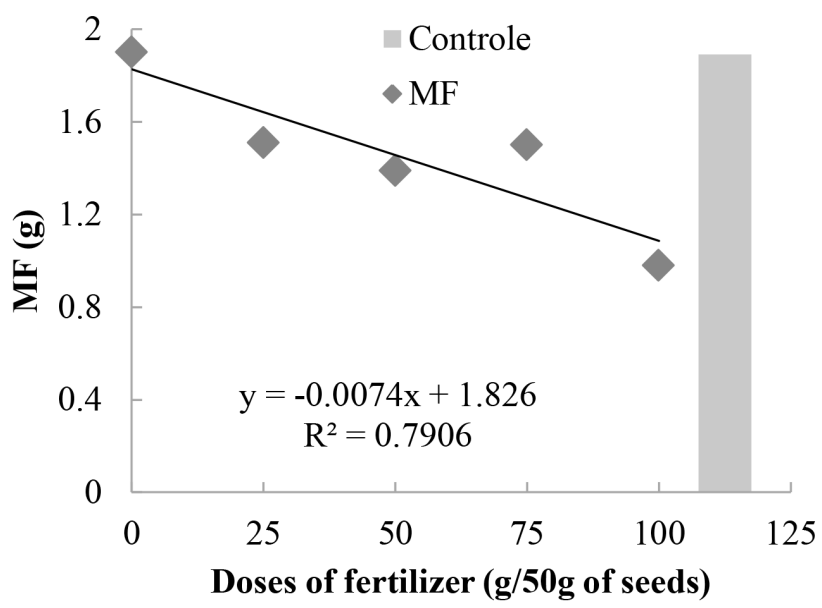

(c)

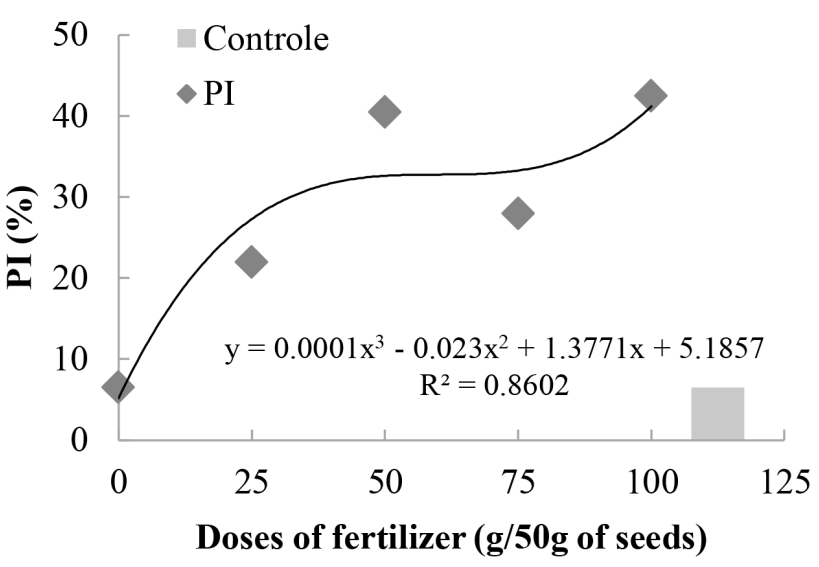

(b)

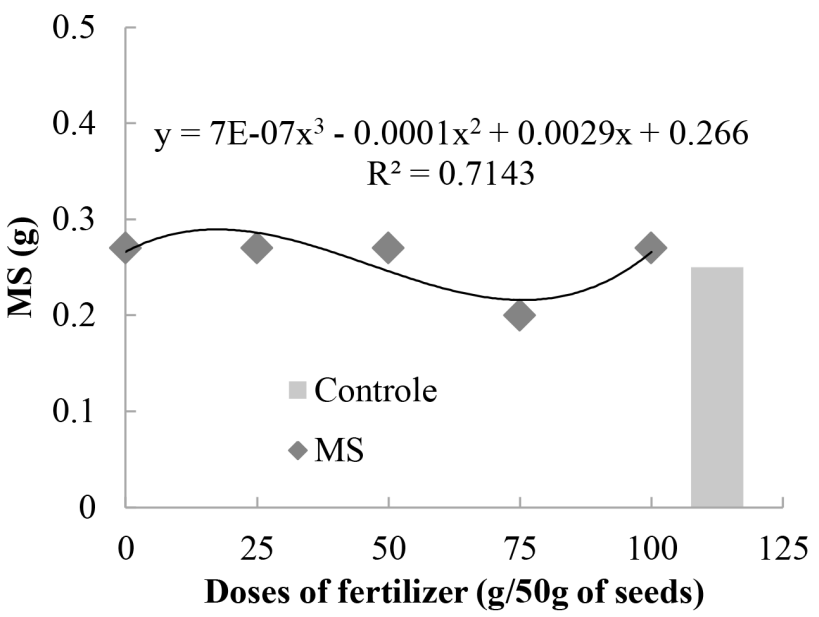

(d)

Figure 3. (a) Percentage of abnormal seedlings (PA\%); (b) Percentage of infested seedlings (PI\%); (c) Fresh mass (MF); (d) Dry mass (MS) in seedlings from seeds of vinhatico coated with increasing doses of fertilizer $(0,25,50,75 \mathrm{and} 100 \mathrm{~g} / 50 \mathrm{~g}$ of seeds) and uncoated seeds (grey column). 
be clearly noticed when the results obtained in the control seeds and in the coated seeds without fertilizer are observed in comparison to those of seeds which received increasing doses of fertilizer in their coating. This attack could be linked either to contamination in the fertilizer or to the delay in the germination of these seeds, which was visually observed during the experiment, thereby damaging the germination with the higher proliferation of fungi.

According to [21], the sanitary quality of the seeds of forest species is an important factor in germination, because contaminated seeds increase losses through decay, abnormalities and damaged seedlings.

Second [22], the seeds can suffer attacks of pathogens in the field and during the harvesting, drying process and seed processing, affecting their quality and reducing their ability to germinate, in addition to causing damage to newly emerged seedlings.

Analyzing the fresh mass (FM) in Figure 3(c), it can be observed decreasing linear behavior along with increased doses of fertilizer in the coating, but it is important to note that there was no significant difference between the control and the seeds coated without fertilizer. This makes it clear that the reduction of FM is not caused by the coating, but by the doses of fertilizer. In seeds coated with doses of fertilizer, besides the reduction of germination, there was also reduction in the GSI, and this delay in germination may be responsible for the lower development of the fresh mass of the seedlings.

Similar results were found by [23] analyzing watermelon seeds coated with different doses of zinc, when it was observed that zinc reduced the vigor of the seeds through tests of length, fresh and dry mass of seedlings.

Analyzing Figure 3(d), it can be observed cubic regression for the variable dry mass (DM) of seedlings, where it is highlighted a decrease in DM in the treatment with $75 \mathrm{~g}$ of fertilizer. The highest values for this variable were found in seeds coated without fertilizer, $50 \mathrm{~g}$ and $100 \mathrm{~g}$ of fertilizer, presenting $0.27 \mathrm{~g}$ of DM in each treatment, which were not bettered by any other treatment. This result shows that even though the fertilizer was prejudicial to the germination, it is not prejudicial to the development of seedlings.

In the greenhouse, the emergence (E) of seedlings was reduced with the increase of doses of fertilizer, but no significant difference was observed between the control seeds and the seeds coated without fertilizer, because they presented high index of emergence, reaching $81 \%$ of emergence against $40 \%$ to $50 \%$ in seeds coated with fertilizer, showing a quadratic behavior of decrease, in which fertilizer in the coating of seeds was harmful to their emergence (Figure 4(a)).

The emergence speed index (ESI) showed decreasing linear behavior in relation to the increase in doses of fertilizers and showed similar results to those obtained in the laboratory for GSI, when seeds coated without fertilizer presented largest ESI than seeds coated with fertilizer in the composition of the coating (Figure 4(b)). 


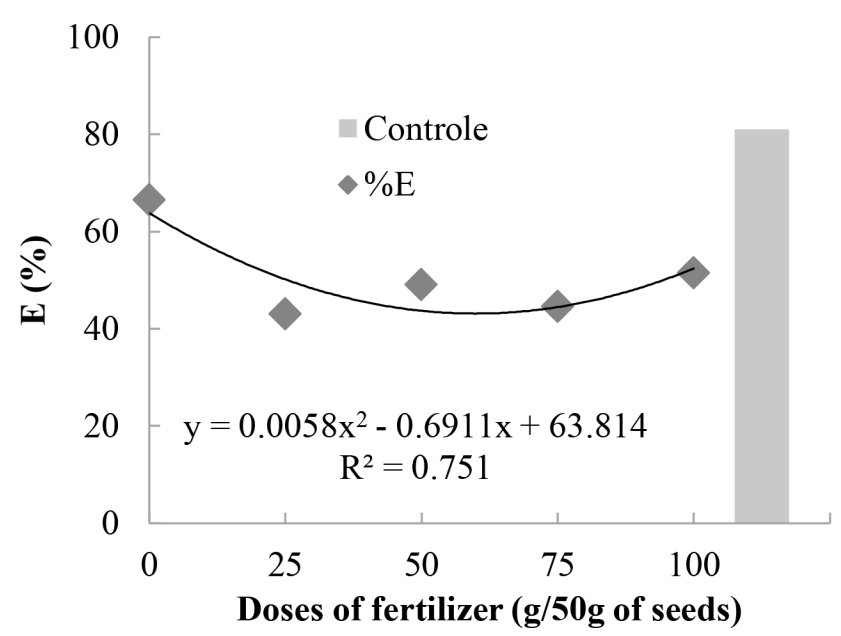

(a)

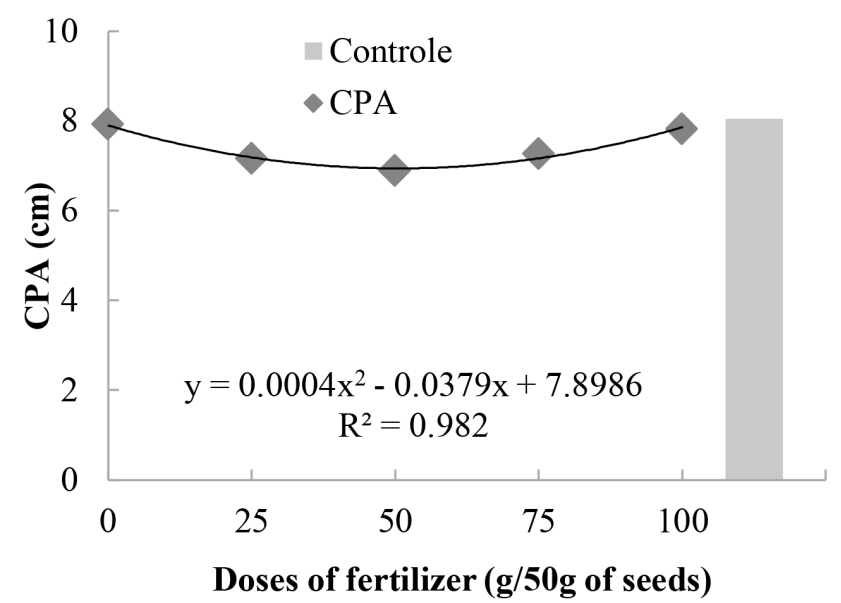

(c)

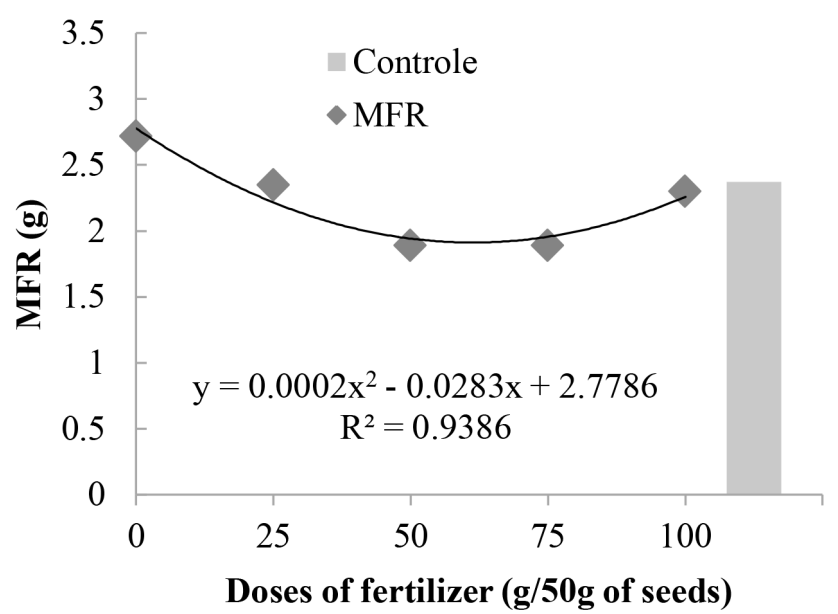

(e)

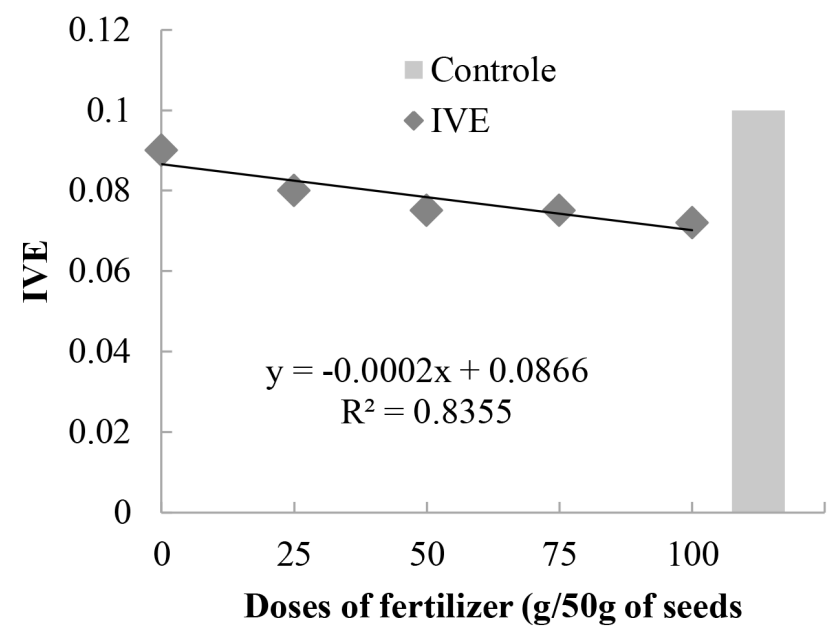

(b)

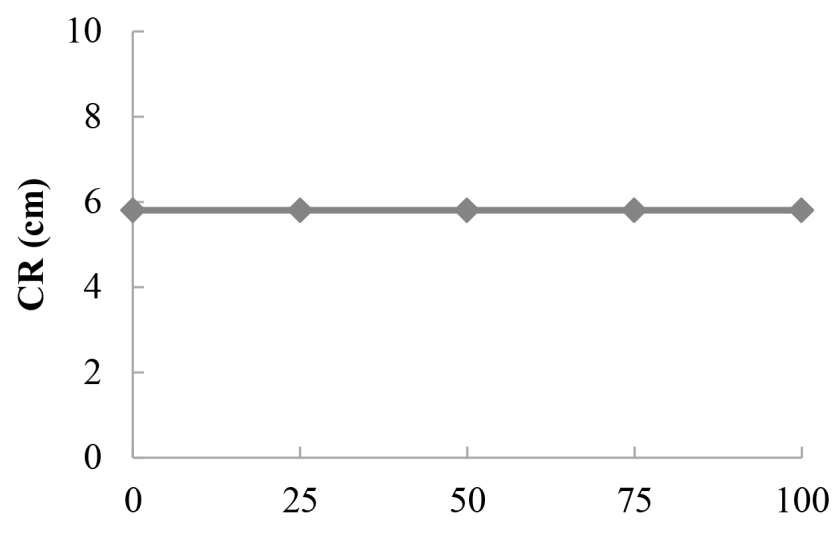

Doses of fertilizer (g/50g of seeds)

(d)

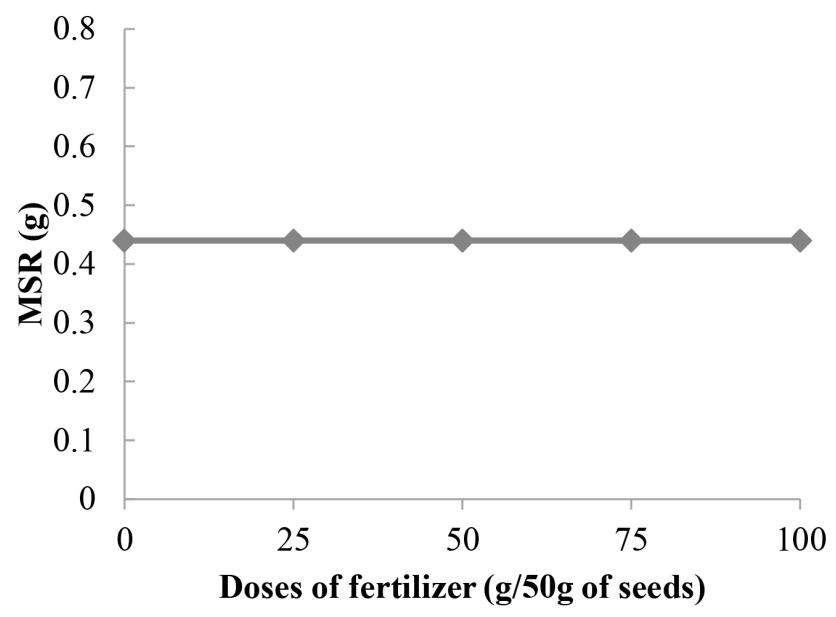

(f)

Figure 4. (a) Percentage of emergence (E\%); (b) Emergence speed index (IVE); (c) Length of aerial part (CPA); (d) Length of the root (CR); (e) Fresh mass of root (MFR); (f) Dry mass of root (MSR) of vinhatico seedlings in the greenhouse, 60 days after sowing. 
Similar results were found by [24], who concluded that the coating of seeds of Brachiaria brizantha cv. Marandu reduced the speed of emergence and germination of seedlings.

[25] working with pelleted lettuce seeds, observed that all the pellets presented percentage of emergence similar to that obtained with non-pelleted seeds, but the pellets caused delay in the emergence.

Already [20] by analyzing the effect of single superphosphate and triple superphosphate as filling material in the pelletization of seeds of mutamba, in doses of $50 \%$ and $100 \%$, observed that the fertilizer negatively compromised the percentage of emergence of seedlings, and stated that the concentration of fertilizer used to pelletize the seeds is decisive in the outcome of germination of the seeds.

On the other hand, [26] pointed out that the pelletized seeds of lettuce had a higher percentage of seedling emergence in the field than the non-pelletized seeds. [27] also observed that there was no difference between non-pelleted and pelleted tomato seeds as to the emergence of seedlings in the field.

According to the regression analysis, the length of the aerial part (LAP) presented quadratic behavior. The differences between treatments were small, because the LAP reached a maximum of $8.04 \mathrm{~cm}$ in seedlings from seeds without coating and a minimum of $6.89 \mathrm{~cm}$ in seedlings from seeds coated with $50 \mathrm{~g}$ of fertilizer in the coating, with significant differences between these two treatments as it can be observed in Figure 4(c).

The [28] studying the coating of tomato seeds with increasing concentrations of synthetic polymer, noted that the film coating did not change the biometric variables related to the growth of seedlings. Already [29] also reported that the growth of carrot plants was not affected by the seed coat. Thus, it can be observed that the effects of coating are more limited to the physiological potential of seed and probably to the initial growth of seedlings, during a short period after the emergence [30].

The length of the root (RL) reached a maximum of $6.4 \mathrm{~cm}$ in seedlings from seeds coated without fertilizer and a minimum of $5.8 \mathrm{~cm}$ in higher doses of fertilizer (50 and $100 \mathrm{~g}$ ), with no significant differences between the treatments (Figure $4(d))$.

These results show that the fertilizer was not prejudicial to the development of seedlings, whereas they presented themselves to be as vigorous as the seedlings that did not receive fertilizer in the coating, even presenting positive effects in later stages of their development in the field, which cannot be evaluated in this work.

For [31], vigorous seeds produce seedlings with higher rate of growth, because they present greater capacity of transformation and of supply of resources of storage tissues and greater.

The analysis related to the incorporation of these resources by the embryonic 
axis. Fresh mass of the aerial part (FMAP) and to the dry mass of the aerial part (DMAP) did not show significant differences, indicating that these variables were not affected by the increasing doses of fertilizer incorporated into the coating of the seeds of vinhatico.

According to the regression analysis, the variable fresh mass of the root (FMR) presented quadratic behavior (Figure 4(e)) and the variable dry mass of the root (DMR) showed no significant differences between the treatments (Figure 4(f)). For these variables there is a tendency to decrease the mass as the doses of fertilizer are increased, but these results are very close to the results obtained with the control treatment.

Similar results were found by [32] while working with the application of copper in corn seeds. They concluded that for the doses of 1.0, 2.0, 4.0 and $6.0 \mathrm{~g}$ of copper per $\mathrm{kg}$ of seed there was reduction in emergence, but without affecting the dry mass of seedlings that emerged.

The [19], working with the application of zinc in sorghum seeds, observed decrease of the dry mass of the root and of the entire plant, which may have been caused by toxicity in the doses of the nutrient applied to the seeds. According to [33], the lowest production of DMR of sorghum can be attributed to the possible toxicity of zinc, which is characterized by an inhibition of root elongation.

The lowest growth of roots and the lowest production of DRM influence directly the absorption of nutrients and contribute with a fraction of the total dry mass produced. [34] found an increase of $19 \%$ in the concentration of zinc in the dry mass of rice plants, with an application of $4.7 \mathrm{~g} \mathrm{Zn}$ per $\mathrm{kg}$ of seed.

The [35] conducted studies to outline the influence of some fertilizers-such as sodium borate and zinc sulfate-when added to the coating, in the initial quality of the seed, in the emergence and in the potential on the field and in storage of soybean seeds. The seeds were pelletized with the addition of zinc sulfate (250 mg. $\mathrm{kg}^{-1}$ of seed) and there was improvement in their initial quality and potential of production. The authors observed that the performance of seeds pelletized with and without nutrients was better than the control, and the power of germination was held for more than three months without any reduction in quality.

Despite the results obtained, the nutrients added to the coating are needed for plant growth. The application of nutrients might work as an alternative to a uniform distribution of micro-nutrients of easy incorporation and low cost of implementation near the seed, being necessary the study of the effect of doses that are lower than the ones applied in this work.

\section{Conclusions}

The coating increased in $91 \%$ the weight of seeds in the treatment without fertilizer. 
The presence of nutrients in the fertilizers used in the coating of seeds decreases their percentage of germination and of emergence.

The coatings with fertilizer provided higher rates of non-germinated seeds and of infested seedlings.

The coating of the seeds without fertilizer was not harmful to the germination, the GSI, or to the fresh and dry mass of seedlings.

The doses of fertilizer used were harmful to germination, GSI, emergence and ESI, but they were not prejudicial to the development of seedlings.

\section{References}

[1] Lorenzi, H. (2008) Brazilian Trees: Identification and Cultivation of Tree Plants in Brazil. 5th Edition, Instituto Plantarum, Nova Odessa, v.1, 385 p.

[2] Neubert, V.F. (2014) Vegetative Propagation of the Vinhático (Plathymenia Foliolosa Benth) by Minies-Taquia. Master Dissertation, Federal University of Viçosa, Viçosa, MG.

[3] Silva, J.B.C. and Nakagawa, J. (1998) Preparation and Evaluation of Pearls of Lettuce Seeds. Brazilian Horticulture, 16, 151-158. https://doi.org/10.1590/S0102-05361998160000200012

[4] Baudet, L. and Peres, W. (2004) Seed Coating. Seed News, 8, 20-23.

[5] Ávila, M.R., Braccini, A.L., Scapim, C.A., Martorelli, D.T., Albrecht, L.P. and Faciolli, F.S. (2006) Physiological Quality and Yield of Maize Seeds Treated with Micronutrients and Cultivated in the Second Cropping Season. Acta Scientiarum Agrono$m y, 28,535-543$.

[6] De Sousa, D.M.G., Lobato, E. and Rein, T.A. (2002) Phosphorus Fertilization. In: De Sousa, D.M.G. and Lobato, E., Eds., Closed: Soil Correction and Fertilization, Embrapa Cerrados, Planaltina, 147-168.

[7] Gonçalves, E.O., Paiva, H.N., Neves, J.C.L. and Gomes, J.M. (2010) Growth of Sapwood (Mimosa caesalpiniaefolia Benth.) Seedlings under Different Doses of Macronutrients. Scientia Forestalis, 38, 599-609.

[8] Mendonça, E.A.F., Carvalho, N.M. and Ramos, N.P. (2007) Super Sweet Corn Seed Coating (Sh2). Brazilian Journal of Seeds, 29, 68-79.

[9] De Sousa, P.G.F., Vieira, H.D., Amorim, M.M. and Acha, A.J. (2016) Coating with Fungicide and Different Doses of Fertilizer in Vinhatico seeds. African Journal of Biotechnology, 15, 2091-2097. https://doi.org/10.5897/AJB2016.15559

[10] Ministry of Agriculture Livestock and Food Supply (2009) Rules for Seed Analysis. SNDA/DNDV/CLAV, Brasília, 399 p.

[11] Brazil, Normative Instruction (2011) Official Diary of the Union. Brasília, Section 1, 2.

[12] Maguire, J.D. (1962) Speeds of Germination-Aid Selection and Evaluation for Seedling Emergence and Vigor. Crop Science, 2, 176-177. https://doi.org/10.2135/cropsci1962.0011183X000200020033x

[13] Silva, F.A.S. and Azevedo, C.A.V. (2009) Principal Components Analysis in the Software ASSISTAT ${ }^{\oplus}$-Statistical Attendance. In: World Congress on Computers in Agriculture, American Society of Agricultural and Biological Engineers, Reno, 7.

[14] Xavier, P.B., Vieira, H.D. and Guimarães, C.P. (2015) Physiological Potential of 
Stylosanthes cv. Campo Grande Seeds Coated with Different Materials. Journal of Seed Science, 37, 117-124. https://doi.org/10.1590/2317-1545v37n2145982

[15] Gadotti, C. and Puchala, B. (2010) Seed Coating. Informative Abrates, 20, 70-71.

[16] Tobe, K., Li, X. and Omasa, K. (2000) Seed Germination and Radicle Growth of a Halophyte Kalidium capsicum (Chenopodiaceae). Annals of Botany, 85, 391-396. https://doi.org/10.1006/anbo.1999.1077

[17] Scott, J.M. (1989) Seed Coatings and Treatments and Their Effects on Plant Establishment. Advances in Agronomy, 42, 43-83.

[18] Oliveira, J.A., Pereira, C.E., Guimarães, R.M., Vieira, A.R. and Silva, J.B.C. (2003) Effect of Different Pelletizing Materials on the Deterioration of Tomato Seeds during Storage. Brazilian Journal of Seeds, 25, 20-27.

[19] Yagi, R., Simili, F.F., Araújo, J.C., Prado, R.M., Sanchez, S.V., Ribeiro, C.E.R. and Baretto, V.C.M. (2006) Application of Zinc via Seeds and Its Effect on Germination, Nutrition and Initial Development of Sorghum. Brazilian Agricultural Research, 41, 655-660.

[20] Almeida, N.O. (2004) Implantation of Riparian Forests by No-Tillage using Peer-Seeded Seeds. Thesis (PhD in Forest Engineering), Federal University of Lavras, Lavras, $269 \mathrm{p}$.

[21] Martins Netto, D.A.M. and Faiad, M.G.R. (1995) Feasibility and Sanity of Seeds of Forest Species. Brazilian Journal of Seeds, 17, 75-80.

[22] Carneiro, J.S. (1987) Tests of Sanity of Seeds of Forest Essences. In: Soave, J. and Wetzel, M.M.V.S., Eds., Seed Pathology, Cargill, Campinas, 386-393.

[23] Ohse, S., Resende, B.L.A., Lisik, D. and Otto, R.F. (2012) Germination and Vigor of Watermelon Seeds Treated with Zinc. Brazilian Journal of Seeds, 34, 282-292.

[24] Santos, F.C., Oliveira, J.A., Pinho, E.V.R.V., Guimarães, R.M. and Vieira, A.R. (2010) Chemical Treatment, Coating and Storage of Seeds of Brachiaria brizantha cv. Marandu. Brazilian Journal of Seeds, 32, 349-354.

[25] Silva, J.B.C., Santos, E.C. and Nascimento, W.M. (2002) Performance of Pelleted Lettuce Seeds according to the Storage Material and the Drying Temperature of Pellets. Horticultura Brasileira, 20, 67-70. https://doi.org/10.1590/S0102-05362002000100013

[26] Coraspe, H.M. (1993) Evaluation of the Effect of Pelleting on the Vigor of Lettuce Seeds (Lactuca sativa L.). Scientia Agrícola, 50, 349-354. https://doi.org/10.1590/S0103-90161993000300005

[27] Nascimento, W.M., Silva, J.B.C. and Marton, L. (1993) Physiological Quality of Pelleted Tomato Seeds during Storage. Informative ABRATES, 3, 47.

[28] Melo, A.P.C., Seleguini, A., Veloso, V.R.S. and Pereira, J.M. (2015) Coating of Tomato Seeds with Increasing Concentrations of Synthetic Polymers. Ciência Rural, 45, 958-963. https://doi.org/10.1590/0103-8478cr20131335

[29] Hölbig, L.S. (2010) Coating of Carrot Seeds. Brazilian Journal of Seeds, 32, 22-28.

[30] Sampaio, T.G. and Sampaio, N.V. (2009) Coating Seeds of Vegetables. In: Nascimento, W.M., Ed., Vegetable Seed Technology, Embrapa Hortaliças, Brasília, 275-306.

[31] Dan, E.L., Mello, V.D.C., Wetzel, C.T., Poppinigis, F. and Zonta, E.P. (1987) Dry Matter Transfer as a Method of Evaluating the Vigor of Soybean Seeds. Brazilian Journal of Seeds, 9, 45-55. 
[32] Luchese, A.V., Gonçalves, J.R., Luchese, E.B. and Braccini, M.C.L. (2004) Emergence and Absorption of Copper by Corn Plants (Zea mays) in Response to Copper Seed Treatment. Ciência Rural, 34, 1949-1952. https://doi.org/10.1590/S0103-84782004000600044

[33] Marschner, H. (1995) Mineral Nutrition of Higher Plants. 2nd Edition, Academic Press, London, $889 \mathrm{p}$.

[34] Slaton, N.A., Wilson Junior, C.E., Ntamatungiro, S., Norman, R.J. and Boothe, D. (2001) Evaluation of Zinc Seed Treatments for Rice. Agronomy Journal, 93, 152-157. https://doi.org/10.2134/agronj2001.931152x

[35] Srimathi, P., Malarkodi, K., Geetha, R. and Krishnasamy, V. (2002) Nutrient Pelleting to Augument Quality Seed Production in Soybean. Seed Research New Delhi, 30, 186-189.

Submit or recommend next manuscript to SCIRP and we will provide best service for you:

Accepting pre-submission inquiries through Email, Facebook, LinkedIn, Twitter, etc. A wide selection of journals (inclusive of 9 subjects, more than 200 journals) Providing 24-hour high-quality service User-friendly online submission system Fair and swift peer-review system Efficient typesetting and proofreading procedure Display of the result of downloads and visits, as well as the number of cited articles Maximum dissemination of your research work

Submit your manuscript at: http://papersubmission.scirp.org/ Or contact ajps@scirp.org 